\title{
Climate-related risks in the construction of Xiongan New Area, China
}

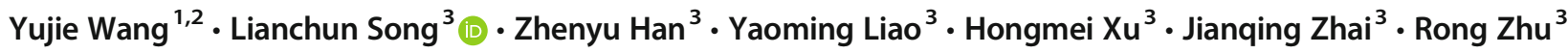

Received: 2 October 2019 / Accepted: 21 May 2020 / Published online: 3 June 2020

(C) The Author(s) 2020

\begin{abstract}
In the paper, we analyze the climate-related risks of rainstorm floods, droughts and water shortages, high temperatures, and heavy hazes in the Xiongan New Area. A warming and drying trend was seen in Xiongan New Area during 1961-2018, as evidenced by the increase in the number of high-temperature days and the maximum rainfall intensity per hour, a decrease in surface water resources and groundwater levels, a reduction in wind speeds, and weakening of the self-purification capacity of the atmosphere. It is estimated that the areas at high risk of floods and heats will increase by 15.7 and $15.6 \%$ in around 2035 relative to 19862005, respectively. Although the runoff in the Daqing River Basin will increase, the construction of Xiongan New Area means that the imbalance between the supply and demand of water resources will remain. Climate change adaptation measures should therefore be improved in the planning and construction of Xiongan New Area. Finally, we discuss the approaches to address climate-related risks in this new area.
\end{abstract}

\section{Introduction}

Under the current background of global warming, cities are increasingly affected by extreme weather and climate events (Alexander et al. 2006; Bai et al. 2018). Global climate change has led to an increase in climate-related risks in China (Wang et al. 2018). The risks of climate change to urban areas are more prominent in China than in other countries (Blumberg and Dphil 2014; Zhai et al. 2018), and extreme weather and climate events - for example, high temperatures and heatwaves, rainstorm floods, and heavy haze-occur frequently (Qin et al. 2015; Mei et al. 2018). The intensity and frequency of these events have increased further in China as the urban climate has been affected by rapid changes in the land surface, enhanced anthropogenic heat release, and high

Lianchun Song

songlc@cma.gov.cn

1 Key Laboratory of Meteorological Disaster, Ministry of Education/ International Joint Research Laboratory on Climate and Environment Change/Collaborative Innovation Center on Forecast and Evaluation of Meteorological Disasters, Nanjing University of Information Science and Technology, Nanjing 210044, China

2 School of Atmospheric Sciences, Nanjing University of Information Science and Technology, Nanjing 210044, China

3 National Climate Center, China Meteorological Administration, Beijing 100081, China emissions of aerosols (Sun et al. 2016; Li et al. 2015; Chen and Oliver 2016). The North China Plain, the heartland of modern China, is likely to experience deadly heatwaves (Kang and Eltahir 2018) in the future and changes to atmospheric circulation patterns induced by global greenhouse gas emissions will contribute to the increased frequency of severe haze events in Beijing (Cai et al. 2017).

The State Council of China has approved the 2018-2035 master plan for Xiongan New Area, located on the North China Plain. Xiongan New Area will undertake the noncapital functions of Beijing, and the master plan optimizes the framework of territorial space development and protection to create an inviting, ecologically balanced low-carbon city. Although Xiongan New Area has a good location, abundant land resources, stable geological conditions, an excellent ecological environment, and strong resource-carrying capacity, it faces a number of problems, including water shortages, severe water pollution, the over-exploitation of groundwater, and the risk of flooding (Xia and Zhang 2017). To achieve the construction goals of Xiongan New Area, the carrying capacity of water resources and the ecological environment should be enhanced through scientific controls (Ge et al. 2017).

It has been shown that Xiongan New Area is experiencing a warming and drying trend (Ma and Ren 2007), evidenced by significantly increased temperatures and decreased precipitation in the Hai River Basin (Zhu et al. 2017), the weakened self-purification capacity of the atmosphere in the BeijingTianjin-Hebei region, more frequent high temperatures 
(Qian and Cao 2018), and frequent extreme precipitation events (Jiang et al. 2018). The average temperature in Xiongan New Area will continue to rise in the future and the frequency and intensity of high temperatures, heatwaves, and rainstorm floods will increase (Wu et al. 2018; Shi et al. 2019). Urban planners and decision-makers need scientific evidence to help them manage risks and develop strategies for climate mitigation and adaptation. Therefore, systematically studying the climate-related risks in Xiongan New Area is of major importance in planning and construction so that the development can adapt to climate change, manage and reduce climate risks, and improve resilience.

Based on the meteorological and hydrological observation data, this paper analyzed the change characteristics of rainstorm floods, droughts and water shortages, heats, and heavy hazes in the Xiongan New Area from 1961 to 2018. We used the regional climate model and hydrological model to project the future climate risks faced by Xiongan New Area and discussed the adaptive strategies. We hope the research could provide scientific support for the planning and construction of the new area in order to improve the society's resilience to climate-related risks.

\section{Data and methods}

\subsection{Research area}

Xiongan New Area, about 100-km southwest of downtown Beijing, is planned to cover Xiongxian, Rongcheng, and Anxin counties, which sit at the center of the triangular area formed by Beijing, Tianjin, and Hebei's provincial capital Shijiazhuang. The New Area will initially cover about 100 $\mathrm{km}^{2}$ and will be expanded to $200 \mathrm{~km}^{2}$ in the midterm and about $2000 \mathrm{~km}^{2}$ in the long term. It is home to Baiyangdian, northern China's largest freshwater wetland. With the eastern Taihang Mountains in the west and the vast North China Plain in the east, the New Area faces Bohai Bay and is part of the Daqing River Basin (Fig. 1).

\subsection{Data}

We use observational data from 1961 to 2018 collected by the National Meteorological Information Center of the China Meteorological Administration. The annual climatological value is the average of 30 years from 1981 to 2010. Drought days are defined as days with different drought grades determined according to the meteorological drought comprehensive index stipulated in national standard GB/T 20481-2017 Grades of Meteorological Drought (National Standard of People's Republic of China GB/T 20481-2006579 2006). High-temperature days (heat days) are defined as days with the highest daily temperature $\geq 35^{\circ} \mathrm{C}$, and rainstorm days are defined as days with daily precipitation $\geq 50 \mathrm{~mm}$. The observed runoff data for the Daqing River Basin are obtained from the Hydrology and Water Resources Bureau of Hebei Province. The water use data are supplied by the Hydrology and Water Resources Bureau of Baoding.

We use a high-resolution $\left(1 / 16^{\circ} \times 1 / 16^{\circ}\right.$, about $\left.6.25 \mathrm{~km}\right)$ combined dynamic and statistical downscaling dataset under the future scenario of RCP4.5, which is downscaled from five GCMs from CMIP5, including CSIRO-Mk3-6-0, ECEARTH, HadGEM2-ES, MPI-ESM-MR, and NorESM1-M (Han et al. 2019; Li et al. 2020; Shi et al. 2019). Five ensemble members with equal weights are used to project the future climate. For more detail on the combined dynamic and statistical downscaling method, please refer to Han et al. (2019).

The socioeconomic data include population density (POP) and gross domestic product (GDP). The estimated POP data are taken from the global $1 / 8^{\circ} \times 1 / 8^{\circ}$ grid data of the SSP2 scenario of the Inter-Sectoral Impact Model Intercomparison Project with a temporal resolution of 1 year. The estimated GDP data are taken from the global $1 / 12^{\circ} \times 1 / 12^{\circ}$ grid data of the SSP2 scenario of the Potsdam Institute for Climate Impact Research with a temporal resolution of ten years. Both datasets are interpolated to a grid of $1 / 16^{\circ} \times 1 / 16^{\circ}$ with a temporal resolution of 1 year by applying the bilinear interpolation method.

\subsection{Calculation of flood and heat disaster risks}

The generalized extreme value distribution method (Chen et al. 2010) is used to simulate the maximum daily precipitation and the maximum continuous precipitation, as well as the maximum temperature and the maximum continuous high-temperature days, to characterize the risks of extreme precipitation and extreme high temperatures, respectively. The two-dimensional hydrodynamic model FloodArea (Xie et al. 2018) is used to establish a dynamic simulation model of rainstorm floods in Xiongan New Area under different heavy rainfall scenarios to determine the risk assessment criteria after comprehensively considering the frequency and depth of floods.

The flood and heat disaster risk are calculated using the method of Wu et al. (2011), which has been widely used in previous studies (e.g., Dong et al. 2014; Xu et al. 2014). This method has a high applicability because the flood or heat risk is understood as an extreme climate index, and the vulnerability of the hazard is based on an exposure and vulnerability level with the following specific details.

(1) Hazard factors assessments. For floods, a normalization is conducted for the RX5day (the maximum consecutive 5-day precipitation), $\mathrm{R} 20 \mathrm{~mm}$ (the number of days with at least $20 \mathrm{~mm}$ of precipitation), the terrain elevation, the 


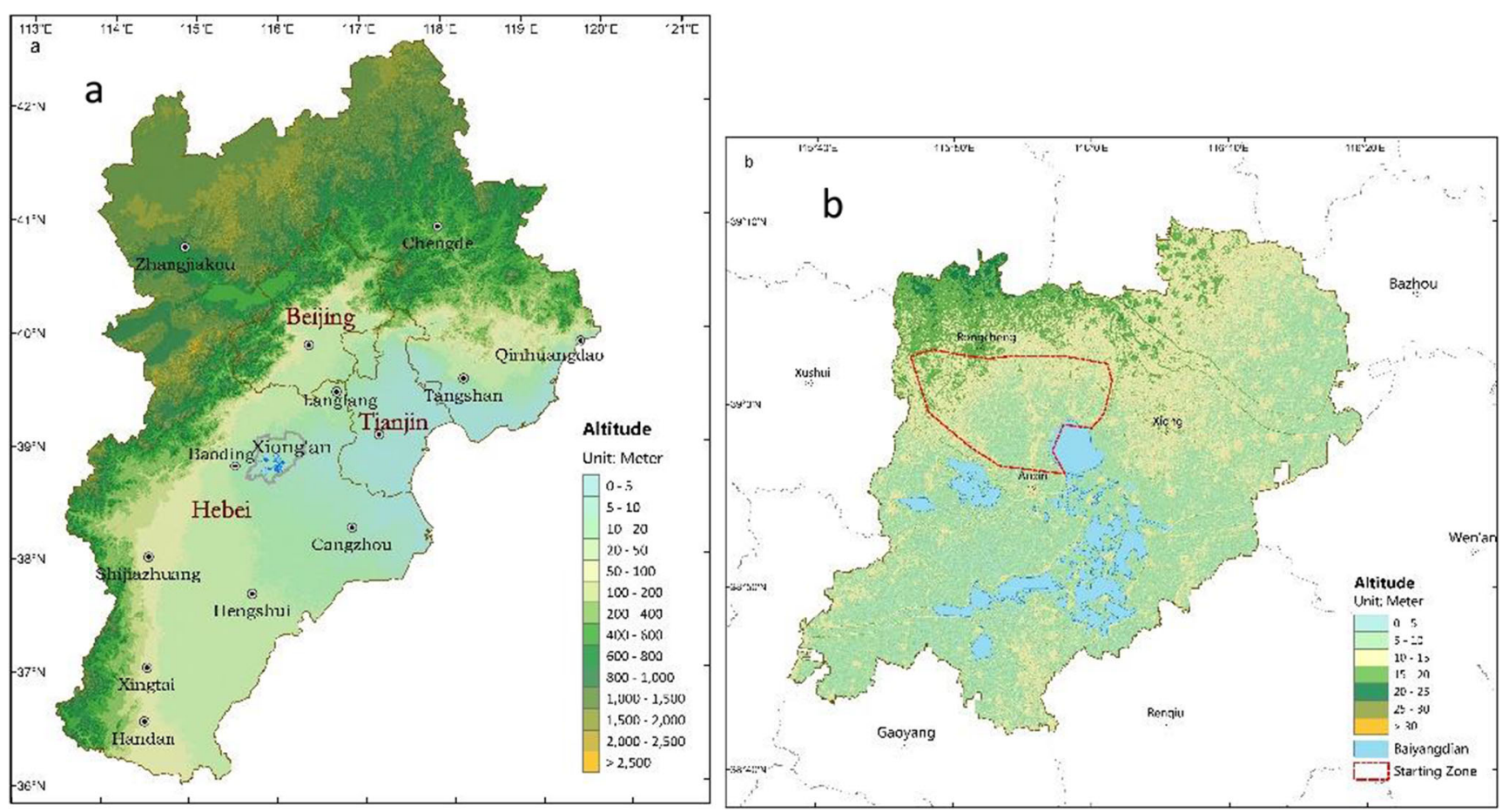

Fig. 1 Topographic map of a the Jing-Jin-Ji region and b Xiongan New Area

standard deviation of elevation, and the distance to water bodies (rivers or lakes). The five normalized indicators are weighted with the proportions $0.35,0.25,0.06,0.12$, and 0.22 . The normalized results are then added to give the flood hazard risk index. For heat, a normalization is conducted for the annual maximal daily maximum temperatures (TXx), annual maximal daily minimum temperatures (TNx), and number of heat days (SU35). The three normalized indicators are then added to form the heat hazard risk index with equal weights.

(2) Vulnerability assessment. The normalized POP and GDP are weighted based on experience. A projection model of the vulnerability to flood hazards is established using the formula $\mathrm{VF}=0.5 \times \mathrm{DPOP}+0.5 \times \mathrm{DGDP}$, where $\mathrm{VF}$ is the vulnerability index and DPOP and DGDP are the normalized POP and GDP, respectively. The model of vulnerability to heat hazards is established using the formula $\mathrm{VH}=0.6692 \times \mathrm{DPOP}+0.3308 \times \mathrm{DGDP}$, where VF is the vulnerability index and DPOP and DGDP are the normalized POP and GDP, respectively. The calculated vulnerability index is then standardized, where 1 is regarded as the maximum value of the vulnerability index in all grids, so the standardized ratio of $\mathrm{VF}$ or $\mathrm{VH}$ in each grid is the vulnerability level of that grid.

(3) Disaster risk assessment. Based on the formula risk = hazard $\times$ vulnerability (vulnerability and exposure), the flood or heat disaster risk index (0-1) over the BeijingTianjin-Hebei region can be calculated. The disaster risk is divided into five levels: I, 0-0.02; II, 0.02-0.05; III, $0.05-0.1$; IV, 0.1-0.2; and V, 0.2-1.0.

\subsection{Hydrological model}

The Soil and Water Assessment Tool (SWAT) model is used to estimate the impact of future climate change on runoff. Different water demand scenarios are set according to the plans for Xiongan New Area to analyze the future water supply and demand risk. The volumes of monthly runoff at Fuping Station in the Sha River Basin, Daomaguan Station in the Tang River Basin, and Zijingguan Station in the Juma River Basin during the time periods 1961-1985 and 19862016 are taken to calibrate and validate the SWAT, respectively. The historical meteorological data used to drive the SWAT are CN05.1 data with a horizontal resolution of $0.5^{\circ}$ $\times 0.5^{\circ}$ developed by the National Climate Center ( $\mathrm{Wu}$ and Gao 2013).

\section{Results}

\subsection{Rainstorm flood}

\subsubsection{Change in precipitation}

Xiongan New Area is located on the northern edge of the East Asian monsoon. The annual climatological precipitation is $481 \mathrm{~mm}$, with $78 \%$ of rainfall concentrated between June and September. Precipitation in winter accounts for $<2 \%$ of the total annual precipitation. The annual variability of precipitation is large and is influenced by the intensity of the summer monsoon. The highest annual precipitation ( $869 \mathrm{~mm}$ in 1988) 
is more than three times the lowest annual precipitation (254 $\mathrm{mm}$ in 1968). During the time period 1961-2018, the annual precipitation and number of rainfall days slightly decreased at rates of $8.8 \mathrm{~mm} / 10 \mathrm{a}$ and 1.5 days $/ 10 \mathrm{a}$, respectively (Fig. 2a, b). The inter-decadal variation in precipitation is very clear. The average annual precipitation reached an historical high of $538 \mathrm{~mm}$ in the 1960s and an historical low of only
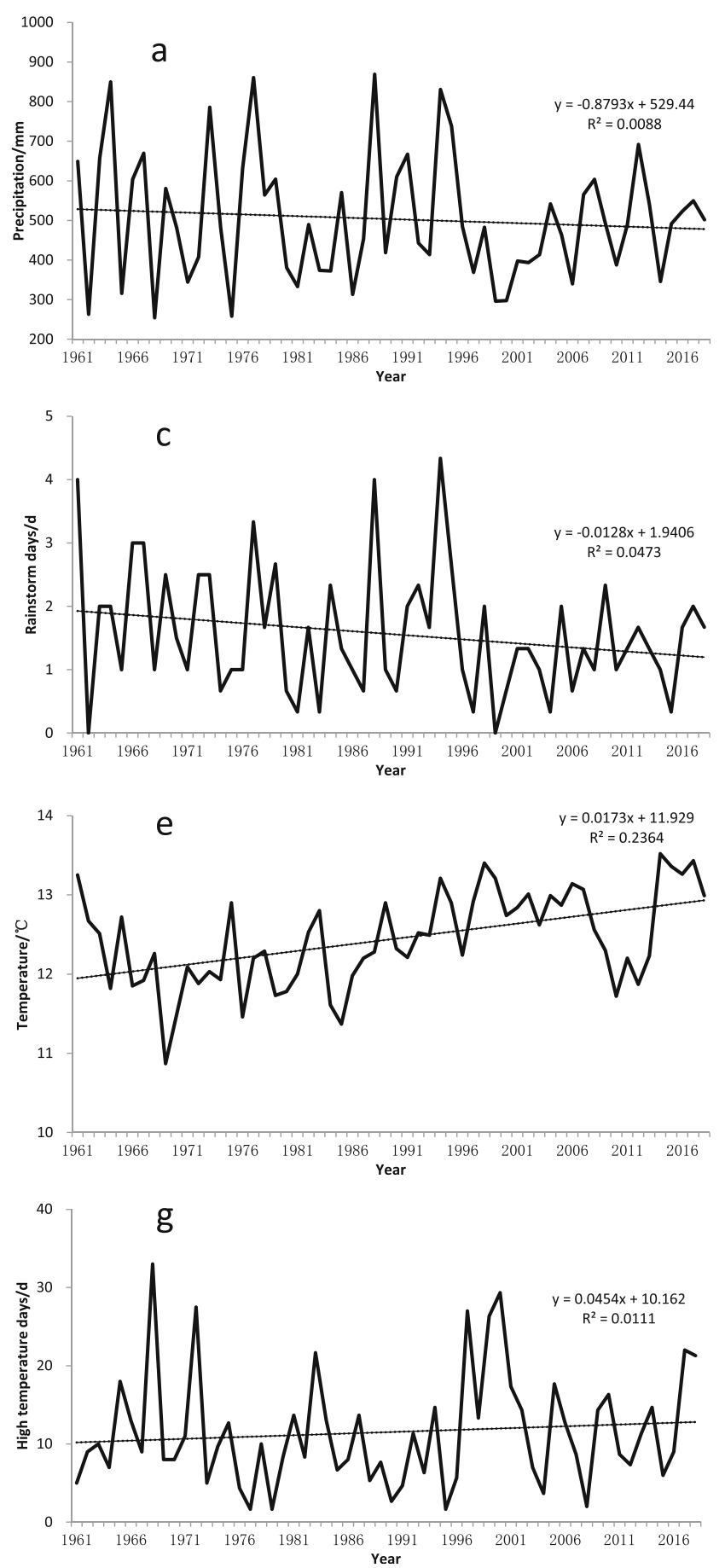

Fig. 2 Variations in major climate factors in Xiongan New Area during 1961-2018. a Annual precipitation, b annual number of rain days, c annual number of rainstorm days, $\mathbf{d}$ maximum rainfall in $1 \mathrm{~h}$, e annual
$460 \mathrm{~mm}$ in the 2000s. The annual number of normal rainstorm days is 1.4 (Fig. 2c) and the longest period of continuous precipitation is 5.0 days. The average maximum daily precipitation is $71.7 \mathrm{~mm}$, and the maximum amount of continuous precipitation is $96.2 \mathrm{~mm}$. During the time period 1961-2018, the hourly maximum rainfall intensity showed an increasing trend of an average of $1.5 \mathrm{~mm} / 10 \mathrm{a}$ (Fig. $2 \mathrm{~d}$ ). The rainfall

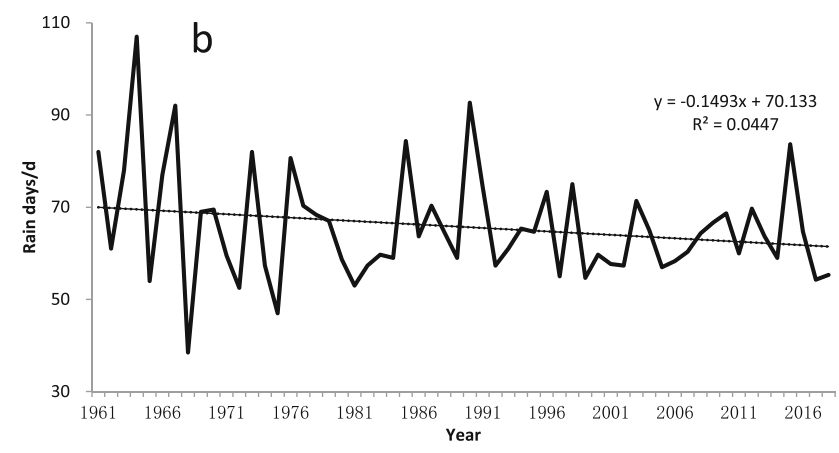

d
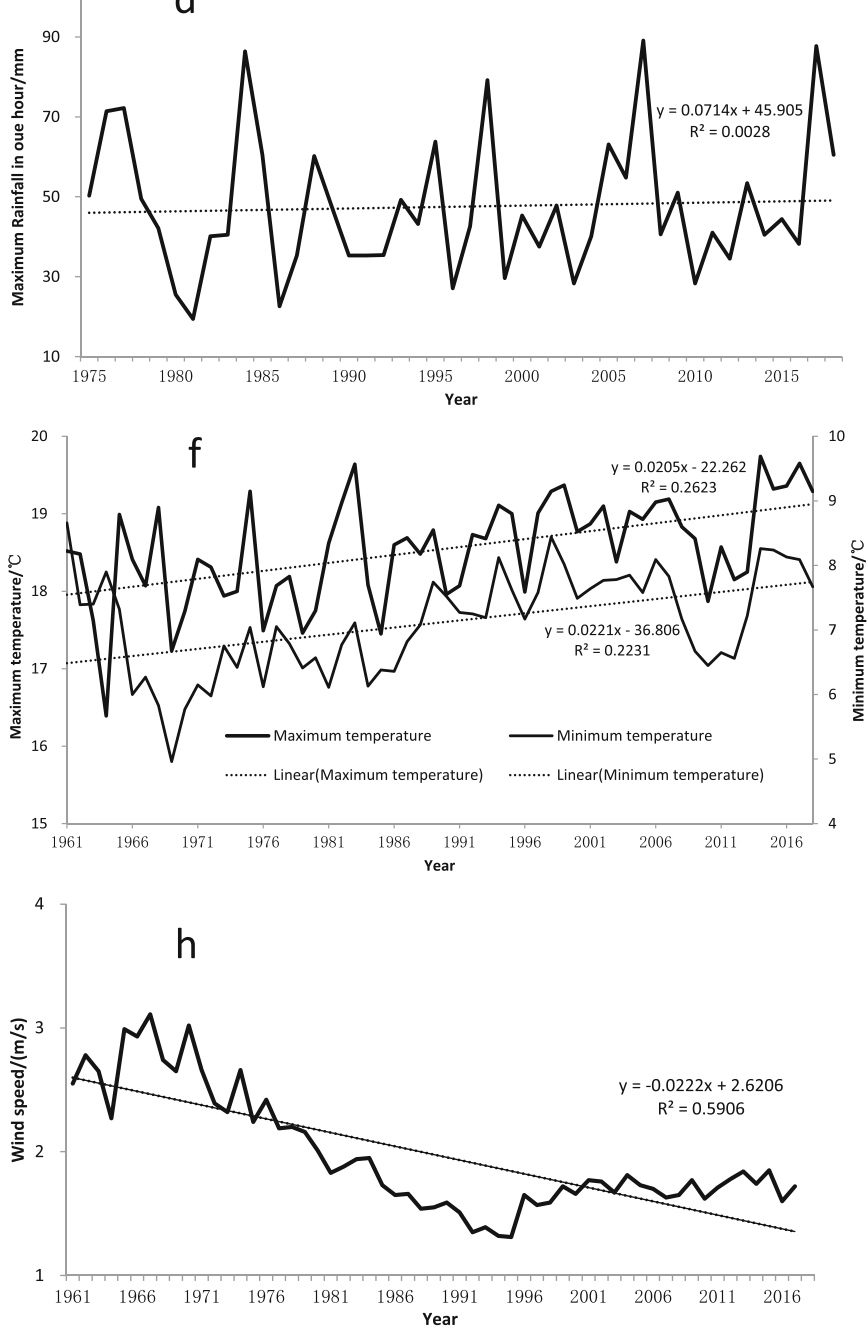

average temperature, $\mathbf{f}$ annual average maximum and minimum temperatures, $\mathbf{g}$ annual number of high-temperature days, and $\mathbf{h}$ annual average wind speed 
intensity at different return periods during 1991-2018 increased by 16-29\% from the 1961-1990 level (Table 1).

\subsubsection{Flood hazard}

Rainstorm flood refers to a flashflood or waterlogging with heavy rainfall. It is one of the most common natural hazards in Xiongan New Area and occur at a high frequency, causing great destruction and heavy economic losses. A total of 139 flood events have occurred in Xiongan New Area over the past 300 years, with, on average, a flood event occurring once every 2 to 3 years. Floods were frequent and severe during the time periods 1796-1827, 1886-1898, and 1948-1965 (Hao et al. 2018). A catastrophic flood took place in the Hai River Basin in early August 1963. As a result, the water level in Baiyang Lake rose and almost all of Anxin and Xiong counties were flooded. Xiongan was affected by a largescale and long-term flood hazard for nearly 2 months. From 19 to 21 July 2016, the cumulative volumes of precipitation in Rongcheng, Anxin, and Xiong counties were 176, 213, and $192 \mathrm{~mm}$, respectively, and the maximum daily precipitation in Rongcheng and Anxin counties were at record highs of 168 and $205 \mathrm{~mm}$, respectively, affecting 517,000 people in Xiongan.

We use the extreme value distribution function to fit the return period of area rainfall in Xiongan New Area and obtain the area rainfall of Xiongan New Area with a return period of $N$ years. The dynamic submergence process of rainstorm floods is simulated by the hydrodynamic model FloodArea. In combination with the impact-based flood risk assessment criteria, the submergence range and depth of rainstorm flood in Xiongan New Area are obtained (Table 2). For a rainstorm that occurs once every 10 years, $80 \%$ of Xiongan New Area reaches a flood depth $<20 \mathrm{~cm}$, which has only a small impact. With the extension of the return period, the area affected by heavy and extremely heavy rainstorms increases. For a rainstorm that occurs once every 50 years, the area with a flood depth of 20-60 $\mathrm{cm}$ reaches $904.6 \mathrm{~km}^{2}$, and the area with a flood depth of $>60 \mathrm{~cm}$ reaches $37.1 \mathrm{~km}^{2}$. Based on these criteria, we obtain the flood risks in Xiongan New Area (Fig. 3). In general, the northern and southeastern parts of the area are subject to high flood risks. Most of the initial development zone is at moderate and high risk of floods,

Table 1 Return periods of daily maximum precipitation $(\mathrm{mm})$ during two time periods in Xiong'an New Area

\begin{tabular}{lllll}
\hline Time period & 10-year & 20-year & 30-year & 50-year \\
\hline $1961-1990$ & 46.5 & 53.8 & 58.0 & 63.2 \\
$1991-2018$ & 53.9 & 63.8 & 69.9 & 78.0 \\
Rate of increase (\%) & 16 & 19 & 21 & 23 \\
\hline
\end{tabular}

and part of Xiongan New Area is at extremely high risk of floods.

\subsubsection{Future flood risk}

The regional climate model RegCM4 is used to predict the future changes in climate in Xiongan New Area and the surrounding areas based on statistical downscaling data at a high resolution of $6.25 \mathrm{~km}$ under the RCP4.5 scenario (Shi et al. 2019) in the reference period 1986-2005. The results show that R95P, RX5day, R1mm, R10mm, and R20mm will generally increase in the future; in particular, intense precipitation during the time period 2026-2045 will increase by $34.1 \%$. Most of the Beijing-Tianjin-Hebei region is grade I risk in the reference period, accounting for $88.2 \%$ of the total area, whereas grade III and higher risks are mainly in the downtown regions of the plain areas. Xiongan is mainly at grade I risk (Fig. 4a). It is estimated that the area of Xiongan at grade II risk will increase from $11.8 \%$ in the reference period to $84.3 \%$ at about 2035, whereas the area at grade $\mathrm{V}$ risk will increase to $15.7 \%$ (Fig. 4b). Both the population and economic volume of Xiongan are planned to increase markedly, and the risk of the initial development zone will also rise to grade $\mathrm{V}$ by about 2035.

\subsection{Drought and water shortage}

\subsubsection{Drought hazard}

Xiongan New Area is usually affected by a moderate and higher drought risk on 57.3 days and a longest continual drought of an average of 31.6 days annually. During the time period 1961-2018, the average annual number of drought days showed a clear inter-decadal feature, with the most drought days (247 days) in 1968, followed by 1975, 1999, and 2006, all with $>150$ drought days (Fig. 2d). There were six extreme drought events in North China after 1951. A spring-summer drought occurred in Hebei Province in 1975, leading to 190 days of drought in Xiongan New Area. The groundwater levels decreased sharply and the production of crops such as wheat and maize was severely affected. Drought continued for a long time in central and southern Hebei Province in 1999, coupled with abnormally high temperatures that led to serious losses of soil moisture. There were 160 drought days in Xiongan New Area in 1999 and a serious drought in Xiong County. Serious winter-spring and autumn droughts swept through Hebei Province in 2006. The average number of drought days in Xiongan New Area reached 170. Drought had a profound impact on the growth of winter wheat and autumn sowing, and some areas were affected by a shortage of drinking water. 
Table 2 Return periods of $24-\mathrm{h}$ precipitation $(\mathrm{mm})$, flood depth $(\mathrm{m})$, and flood area $\left(\mathrm{km}^{2}\right)$ in Xiong'an New Area

\begin{tabular}{llllll}
\hline $\begin{array}{l}\text { Return period } \\
\text { (years) }\end{array}$ & $\begin{array}{l}\text { Precipitation } \\
(\mathrm{mm})\end{array}$ & $\begin{array}{l}<5 \mathrm{~cm} \text { (lowest } \\
\text { impact) }\end{array}$ & $\begin{array}{l}5-20 \mathrm{~cm} \text { (low } \\
\text { impact) }\end{array}$ & $\begin{array}{l}20-60 \mathrm{~cm} \text { (high } \\
\text { impact) }\end{array}$ & $\begin{array}{l}>60 \mathrm{~cm} \text { (highest } \\
\text { impact) }\end{array}$ \\
\hline 10 & 117.8 & 735.1 & 686.8 & 340.8 & 7.2 \\
20 & 141.5 & 729.9 & 449.5 & 572.6 & 17.9 \\
30 & 157.0 & 728.0 & 249.3 & 766.0 & 26.7 \\
50 & 177.1 & 723.7 & 104.5 & 904.6 & 37.1 \\
\hline
\end{tabular}

\subsubsection{Change in water resource}

Xiongan New Area contains Baiyang Lake in the Daqing River Basin. The annual average runoff is about 2.23 billion $\mathrm{m}^{3}$, with $85 \%$ of the total from mountainous areas. Influenced by a monsoon climate, $60-80 \%$ of the annual surface runoff is concentrated in June-September, resulting in extreme interannual variations: the maximum runoff is 15 times the minimum runoff. During the time period 2005-2016, the average water resources in three counties of Xiongan New Area totaled 160 million $\mathrm{m}^{3}$ with a per capita resource of $147 \mathrm{~m}^{3}$. The total water supply was 250 million $\mathrm{m}^{3}$, with a water deficit of nearly 90 million $\mathrm{m}^{3}$ per year (about $36 \%$ ). More than $90 \%$ of the total water supply is from groundwater.
The decrease in annual precipitation has led to a sharp decrease in natural runoff in the mountainous areas of the Daqing River Basin. The annual runoff at three hydrological stations (Zijingguan in the Juma River Basin, Fuping in the Sha River Basin, and Daomaguan in the Tang River Basin) in the mountainous areas of Baiyang Lake in the Daqing River Basin during the time period 1961-2016 decreased at a rate of 130 million $\mathrm{m}^{3} / 10 \mathrm{a}$, significant at the $95 \%$ level (Fig.5a), mainly in the summer months. The surface water resources in Xiongan New Area were insufficient to meet demand, and a large amount of groundwater was over-exploited for a long time, leading to a rapid decrease in groundwater levels. During the time period 1976-2016, deep groundwater levels in Anxin County showed a significant long-term downward
Fig. 3 Risk of waterlogging in Xiongan New Area

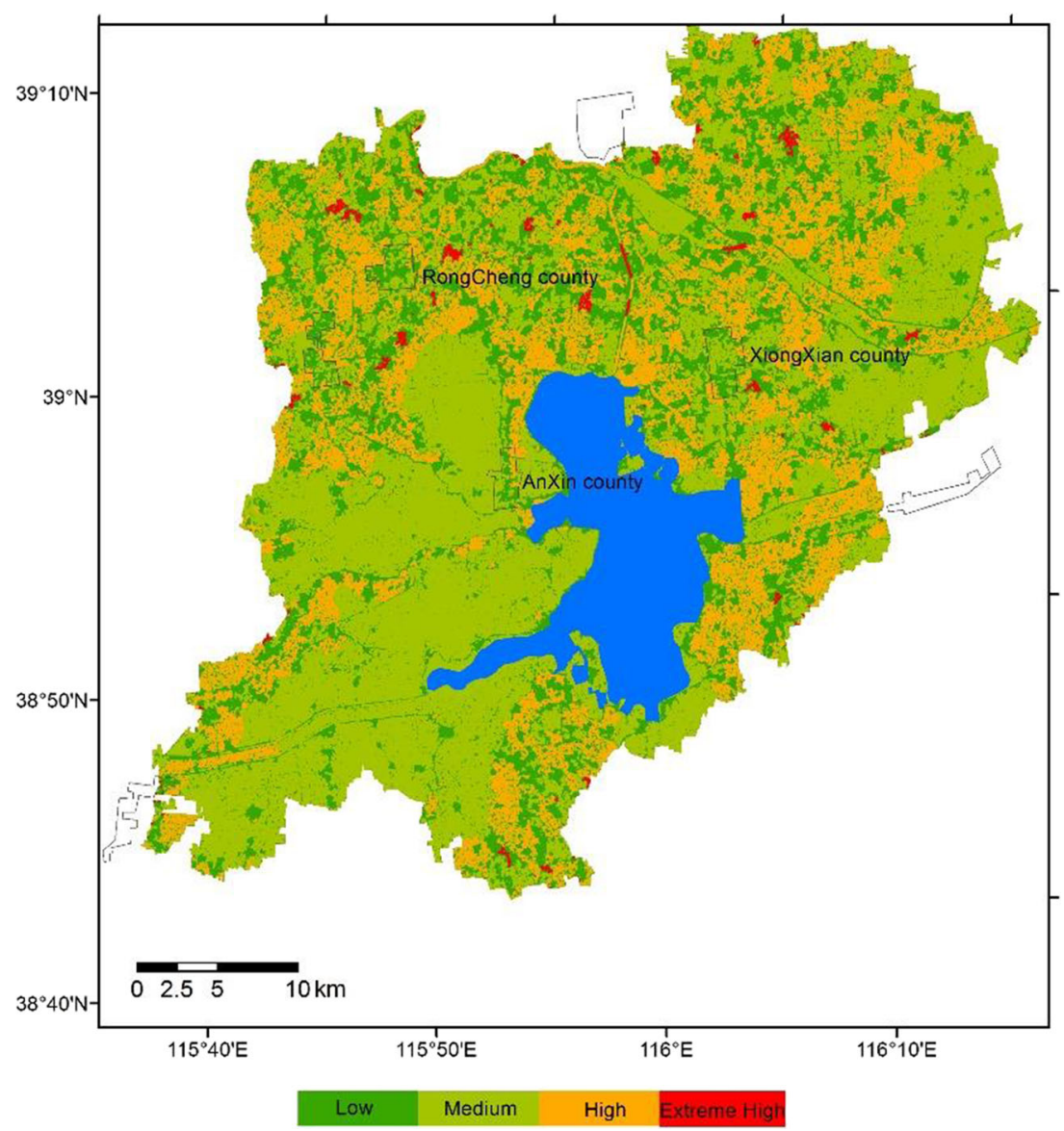



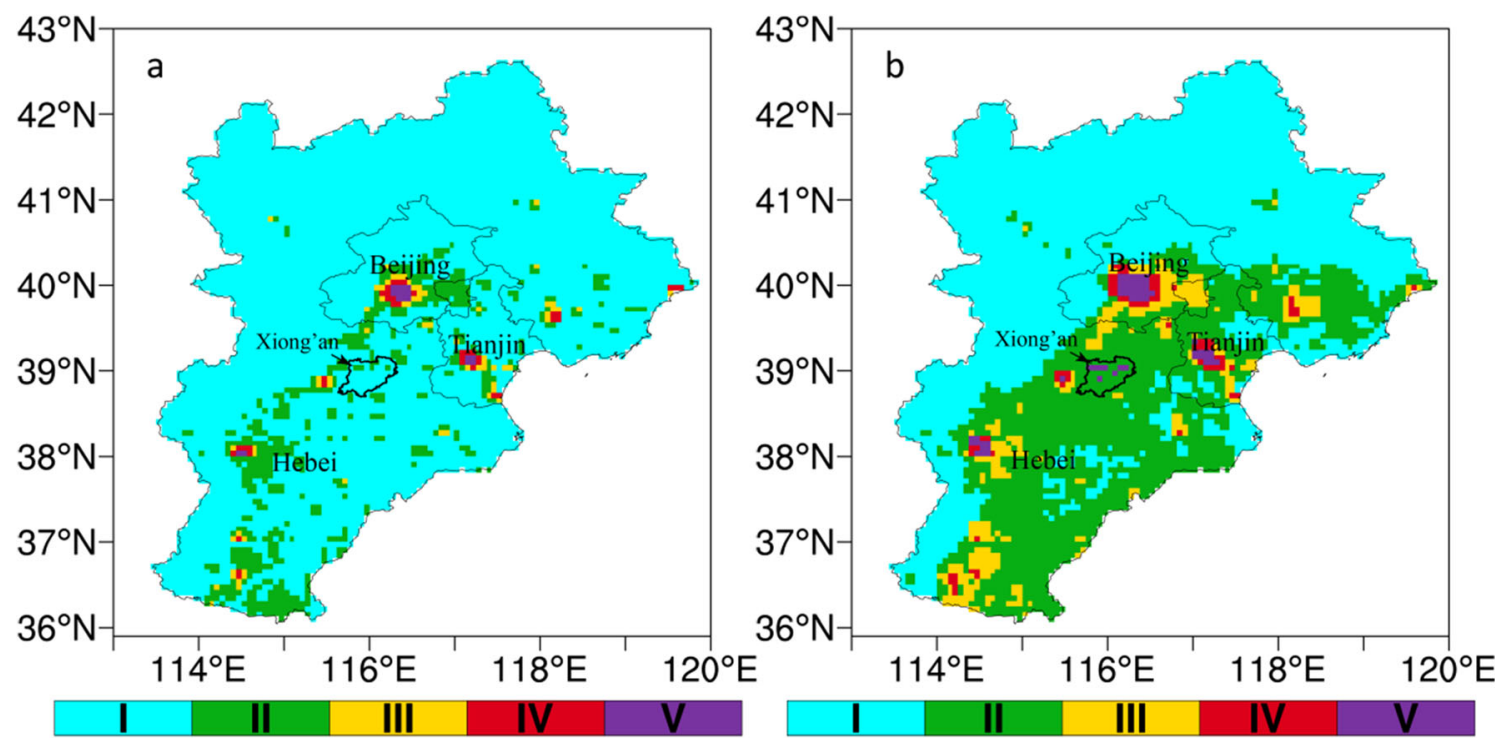

Fig. 4 a Observed and $\mathbf{b}$ projected spatial distribution of flood risk in Jing-Jin-Ji. grades I, II, III, IV, and V represent lowest, lower, medium, higher, and highest risk, respectively

trend (Fig. 5b). The groundwater depth in Anxin County decreased by $38 \%$, from 7.8 to $10.2 \mathrm{~m}$, during the time period 2006-2015, whereas the groundwater depth in Rongcheng County decreased from 9.2 to $22.5 \mathrm{~m}$ and that in Xiongxian County from 17.8 to $19.2 \mathrm{~m}$.

\subsubsection{Projection of future water resource}

Temperatures in Daqing River Basin are projected to rise in the future, precipitation will increase slightly, and the number of extreme heavy precipitation events will increase. Extreme droughts will increase in northern and central areas, whereas the longest period of continual drought days will decrease in the southern area and the basins below Baiyang Lake. The SWAT model predicts that surface runoff in the Daqing River Basin will increase by $11 \%$ in the near future, with a larger increase in the northern area than in the south. Runoff is expected to increase mainly in autumn and winter by 80 and $45 \%$, respectively, whereas runoff in spring will decrease by about $5 \%$ and the runoff in summer will be unchanged (Fig. 6).

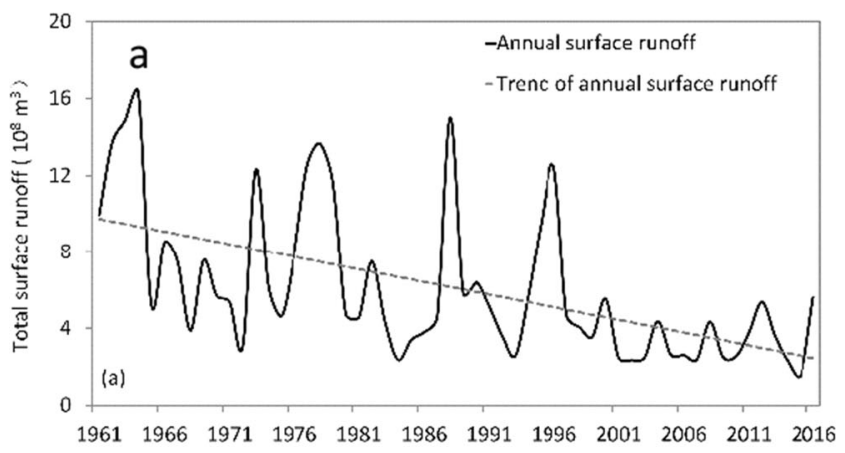

\subsection{High temperature and heat hazard}

\subsubsection{Changes in high temperature}

The climatological annual average temperature, the average maximum temperature, and the average minimum temperature in Xiongan New Area are 12.6, 18.7, and $7.3^{\circ} \mathrm{C}$, respectively, lower than those in regions such as Beijing, Tianjin, Shijiazhuang, and Baoding. This may be related to the heat island effect of large cities and the regulating effect of Baiyang Lake on temperatures (Cui et al. 2015; Zheng et al. 2012). The extreme average annual maximum temperature in Xiongan New Area was $38.2{ }^{\circ} \mathrm{C}$. During the time period 1961-2018, the annual average temperature, maximum temperature, and minimum temperature in Xiongan New Area showed an upward trend, with linear changes of $0.17,0.20$, and $0.21^{\circ} \mathrm{C} /$ 10a, respectively, significant at the 95\% level (Fig.2e, f). There are, on average, 11.8 high-temperature days annually, an increase of 0.8 days $/ 10 \mathrm{a}$ since 1961 (Fig. $2 \mathrm{~g}$ ). The average high temperature first appears on June 2 and lasts until

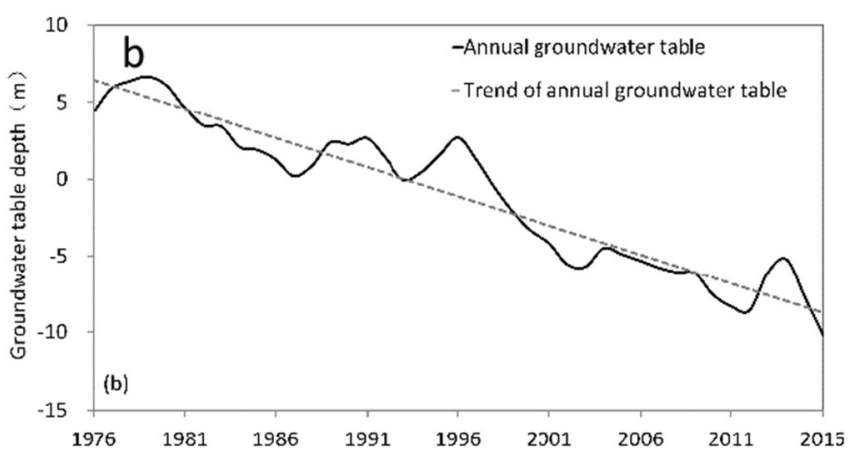

Fig. 5 a Observed annual total surface runoff from the mountainous area in Daqinghe River during 1961-2016 and $\mathbf{b}$ observed annual groundwater table depth in Anxin County during 1976-2016 
Fig. 6 Change in simulated monthly runoff from the mountainous area in Daqinghe River during the time period 2026-2045 relative to the baseline period of 1986-2005

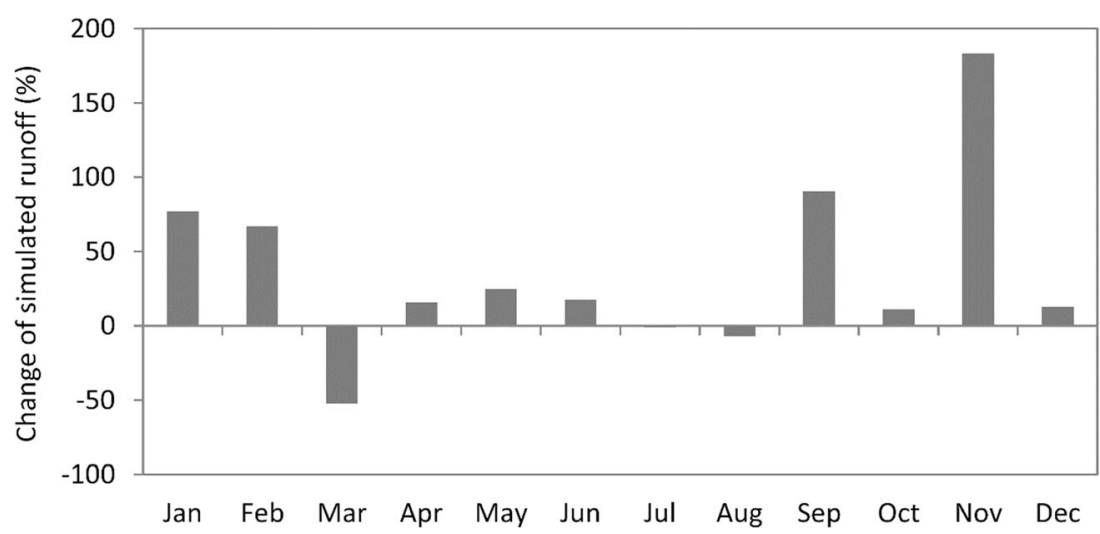

July 22. In 2000, there were 29.3 average high-temperature days in Xiongan New Area, with the highest temperatures in Anxin and Rongcheng counties on July 1 reaching historical records of 41.0 and $41.2{ }^{\circ} \mathrm{C}$, respectively.

\subsubsection{Future heat risk}

The heat disaster risk areas in the Beijing-Tianjin-Hebei region in the reference time period were mainly urban areas with high populations and a high GDP, such as Beijing, Tianjin, Baoding, and Shijiazhuang; $98 \%$ of the Xiongan New Area had a risk below grade II (Fig. 7a). In the near future (2026-2045), however, the ensemble annual average temperature of Xiongan New Area will increase by $1.01{ }^{\circ} \mathrm{C}$ and the daily maximum temperature, the daily minimum temperature, and the number of summer days will increase by $1.38{ }^{\circ} \mathrm{C}, 1.35{ }^{\circ} \mathrm{C}$, and 9 days, respectively. There will be a heat risk zone of grade III along the Hai River Plain east of the Taihang Mountains by about 2035, and the areas with a heat risk

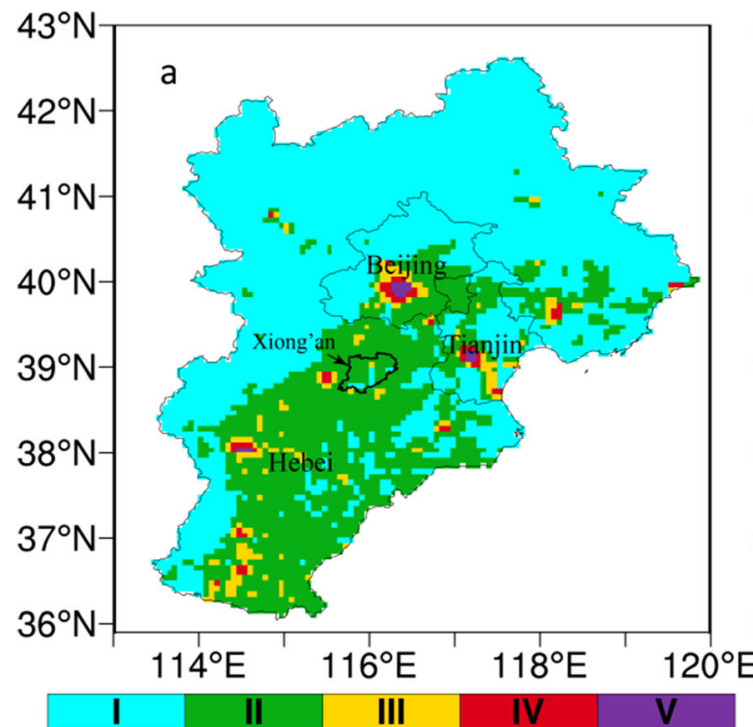

of grade III and above will expand. The area with a heat risk of grade III will expand from 1.96 to $27.45 \%$, and the area with a heat risk of grade $\mathrm{V}$ will expand to $15.59 \%$ (Fig. 7b).

\subsection{Heavy haze}

Xiongan New Area usually has an annual average of 5.1 haze days, significantly fewer than in Beijing, Tianjin, and Hebei (18.4 days). In 2017, the good air quality rate in the BeijingTianjin-Hebei Region was between 38.9 and $79.7 \%$, whereas that in Xiongan New Area was $61.9 \%$, and the concentration of PM2.5 was $68.1 \mu \mathrm{g} / \mathrm{m}^{3}$, better than that in Shijiazhuang and other areas of Baoding.

Located on the leeward side of the Taihang and Yanshan mountains, Xiongan New Area has an annual average wind speed of $1.63 \mathrm{~m} / \mathrm{s}$ and a $28 \%$ frequency of annual breeze $(<1.0 \mathrm{~m} / \mathrm{s})$. The self-purification capacity of the atmosphere is calculated using the method of Zhu et al. (2018). Northern Shijiazhuang and Baoding have

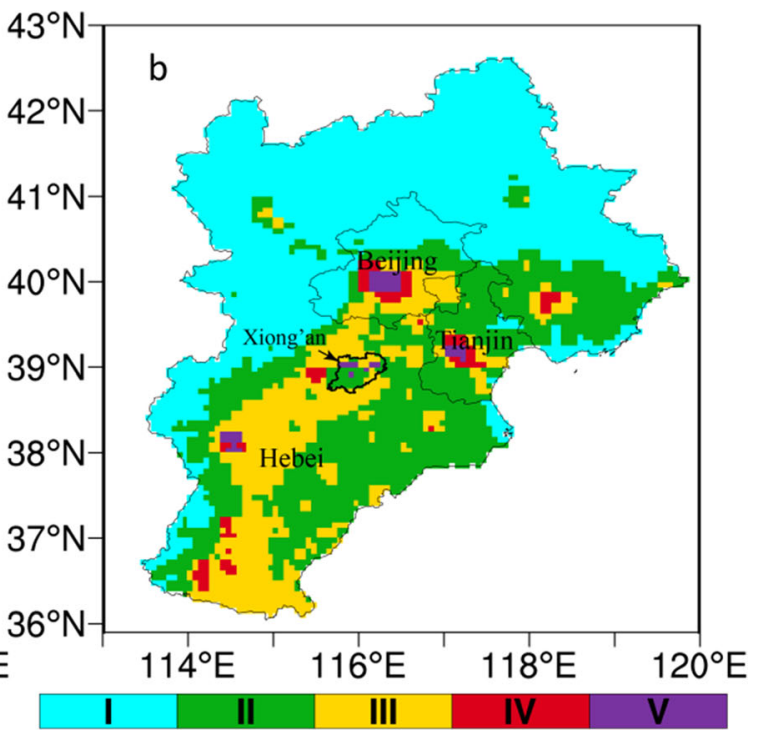

Fig. 7 a Observed and b projected heat risk in Jing-Jin-Ji. Grades I, II, III, IV, and V represent lowest, lower, medium, higher, and highest risk, respectively 

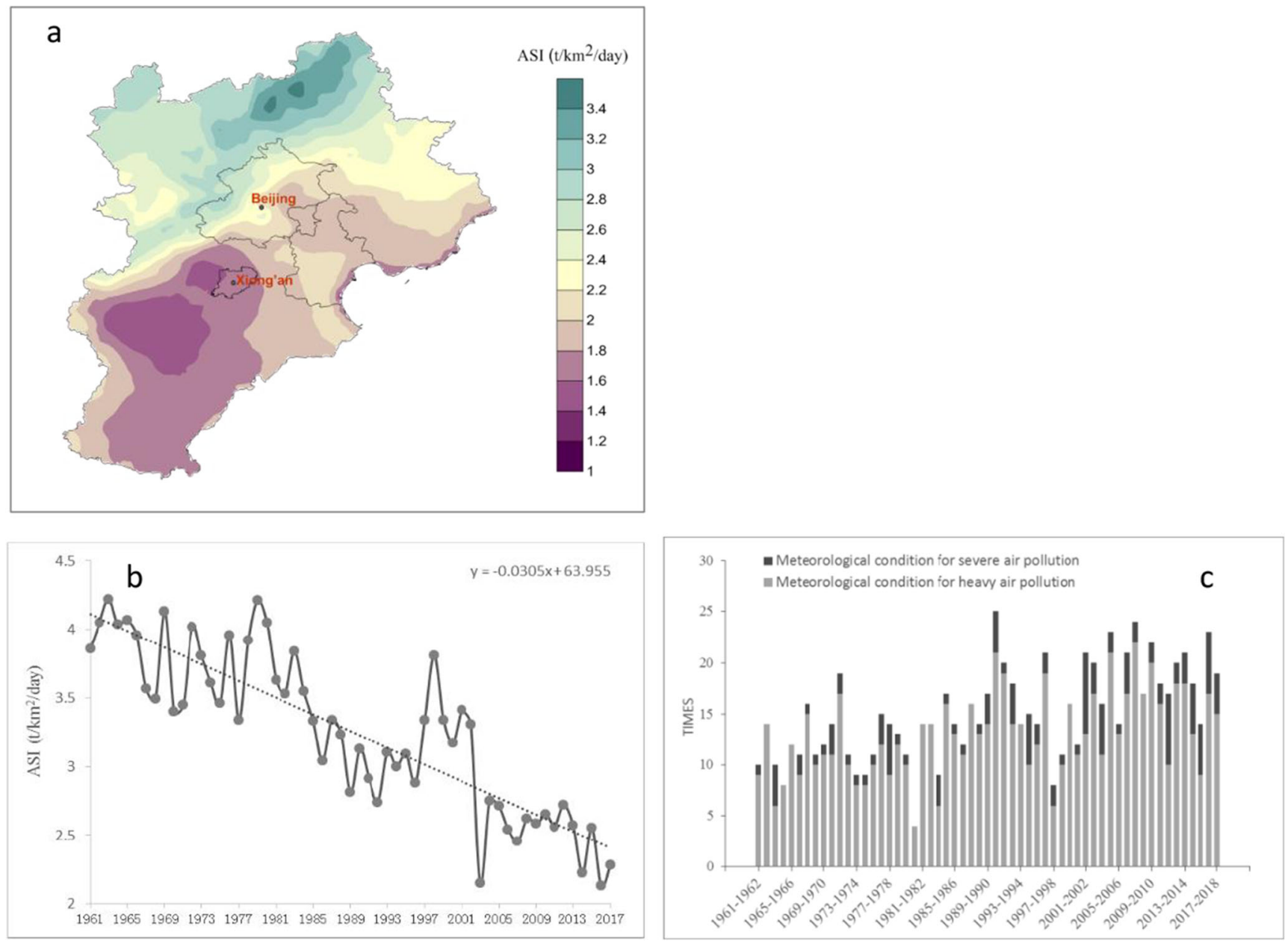

Fig. 8 a Distribution of the annual mean self-cleaning ability index of the atmosphere (ASI) in the Beijing-Tianjin-Hebei region, $\mathbf{b}$ historical changes in the ASI in Xiong'an New District, and $\mathbf{c}$ frequent changes in meteorological conditions above heavy pollution in Baoding in autumn and winter

the lowest self-purification capacity in the BeijingTianjin-Hebei region (Fig. 8a). Xiongan New Area lies in the east of Baoding and the average self-purification capacity of the atmosphere was 1.63 tons $/ \mathrm{km}^{2} /$ day during the time period 2007-2017, lower than that of Beijing, Tianjin, and Shijiazhuang, which is not conductive the diffusion of air pollution and urban ventilation. As a result of climate change, the annual average wind speed and self-purification capacity of the atmosphere in Xiongan New Area significantly decreased at a rate of $0.22 \mathrm{~m} / \mathrm{s} / 10 \mathrm{a}$ (Fig. 2h) and $300 \mathrm{~kg} / \mathrm{km}^{2} / 10 \mathrm{a}$ (Fig. $8 \mathrm{~b}$ ), respectively, during the time period 1961-2018. The frequency of heavy pollution in autumn and winter and these particular meteorological conditions has increased significantly in Baoding, where Xiongan New Area is located, since 1961 (Fig. 8c), with an increase of two events every decade on average to 21 events in 1 year. Heavy pollution in autumn and winter and these particular meteorological conditions occurred seven times in 2011-2012 and 2015-2016.

\section{Discussion and conclusions}

This study shows that, within the Beijing-Tianjin-Hebei region, the Xiongan New Area currently has a suitable climate for urban development but will face high climate-related risks in the future. Our conclusions and proposed countermeasures can be summarized as follows.

(1) During the time period 1961-2018, the annual precipitation and the annual number of precipitation days in Xiongan New Area decreased at rates of $8.8 \mathrm{~mm} / 10 \mathrm{a}$ and 1.5 days $/ 10$ a, respectively, but the maximum rainfall intensity per hour increased by an average of $1.5 \mathrm{~mm} /$ 10a. It is estimated that the annual precipitation and heavy precipitation will increase by 7.4 and $34.1 \%$, respectively, by 2035 relative to the reference period of 1986-2005. Located in the Daqing River Basin, near Baiyang Lake and downstream of several river basins, Xiongan New Area is relatively low-lying and is vulnerable to floods caused by the Daqing River. Most of its 
initial development zone is located in areas at moderate and high risk of floods; in the future, with the increasing frequency and intensity of extreme precipitation, the area at risk of grade II floods will increase from 11.8 to $84.3 \%$ of the reference area and the area at risk of grade $\mathrm{V}$ floods will increase to $15.7 \%$. Therefore, more effort should be made to construct flood control and drainage facilities and improve the design standard for urban drainage systems to reduce the flood risk.

(2) The trend of climate warming and drying has led to an average decrease of 130 million $\mathrm{m}^{3} / 10 \mathrm{a}$ in the total runoff from the Daqing River Basin. Coupled with the increased use of water resources, the balance between the supply and demand for water resources in Xiongan New Area has been affected. The groundwater levels in the three counties of Xiongan New Area have decreased rapidly due to the long-term over-exploitation of groundwater. It is estimated that surface water resources will increase by $11 \%$ by about 2035 but will still be unable to meet current water shortages. In addition, the decrease in spring runoff will aggravate seasonal droughts and water shortages will constrain the sustainable development of Xiongan New Area in the future. At present, the use of water resources is unsustainable: water used for agriculture accounts for $76 \%$ of the total, followed by domestic use of $12.3 \%$, and water for ecosystems of only $0.2 \%$. On the premise of ensuring flood control and drainage, rainstorm flood use projects should be planned and constructed to maximize rainwater storage, infiltration, and purification, so that more flood resources can be turned into accessible surface water and groundwater resources. Inter-basin water transfer should be actively implemented and water for crop production, domestic and ecosystems should be scientifically and rationally distributed.

(3) The annual average temperature, maximum temperature, minimum temperature, and high-temperature days in Xiongan New Area have shown an upward trend over the past 57 years. It is estimated that the annual average temperature will rise by $1.01^{\circ} \mathrm{C}$ in the near future (20262045), the number of summer days will increase by 9 days, the area at the risk of grade III heat will expand from 1.96 to $27.45 \%$, and the area at risk of grade $V$ heat will expand to $15.69 \%$. The risk of high temperatures and heatwaves should be considered in urban planning and construction and the role of Baiyang Lake in increasing air humidity, lowering the surrounding temperatures and alleviating the urban heat island effect, and regulating the microclimate should be maximized.

(4) As a result of the poor self-purification capacity of the atmosphere and poor ventilation conditions in Xiongan New Area, the annual average wind speed and selfpurification capacity of the atmosphere are decreasing as a result of climate change. Urban planning should include building an urban ventilation corridor, achieve zero carbon emissions, and control the discharge of pollutants in Beijing, Baoding, and the southern cities of Hebei.

Acknowledgments We thank the editor and anonymous reviewers who all made very valuable suggestions for improvement of this manuscript. We also thank data providers who all made contributions to the research.

Funding information This work was supported by the National Key R\&D Program of China (Grant No. 2018YFA0606302).

Open Access This article is licensed under a Creative Commons Attribution 4.0 International License, which permits use, sharing, adaptation, distribution and reproduction in any medium or format, as long as you give appropriate credit to the original author(s) and the source, provide a link to the Creative Commons licence, and indicate if changes were made. The images or other third party material in this article are included in the article's Creative Commons licence, unless indicated otherwise in a credit line to the material. If material is not included in the article's Creative Commons licence and your intended use is not permitted by statutory regulation or exceeds the permitted use, you will need to obtain permission directly from the copyright holder. To view a copy of this licence, visit http://creativecommons.org/licenses/by/4.0/.

\section{References}

Alexander LV, Zhang X, Peterson TC (2006) Global observed changes in daily climate extreme of temperature and precipitation. J Geophys Res-Atmos 111:D05109

Bai XM, Dawson RJ, ürge-Vorsatz D, Delgado GC et al (2018) Six research priorities for cities and climate change. Nature 555:23-25

Blumberg G, Dphil SM (2014) Assessing the potential impact of heat waves in cities: Implications for hazard preparation and planning. Procedia Economics and Finance 18:727-735

Cai WJ, Ke L, Liao H, Wang HJ et al (2017) Weather conditions conducive to Beijing severe haze more frequent under climate change. Nat Clim Chang 7:257-263

Chen L, Oliver WF (2016) Impacts of urbanization on future climate in China. Clim Dyn 47:345-357

Chen ZS, Liu ZM, Lu JF (2010) Comparative analysis of parameter estimation methods of generalized extreme value distribution. Acta Sci Nat Univ Sunyatseni 49:105-109

Cui YP, Liu JY, Zhang XZ, Qin YC, Dong JW (2015) Modeling urban sprawl effects on regional warming in Beijing-Tianjing-Tangshan urban agglomeration. Acta Ecol Sin 3:993-1003

Dong SY, Xu Y, Zhou BT, Hou MT et al (2014) Projected risk of extreme heat in China based on CMIP5 models. Clim Chang Res 5:365-369

Ge QS, Yang LS, Jing FJ (2017) Carrying capacity of resource and environment of Xiongan New Area: evaluation, regulation, and promotion. Bull Chin Acad Sci 32:1206-1215

Han ZY, Shi Y, Wu J, Xu Y, Zhou BT (2019) Combined dynamical and statistical downscaling for high-resolution projections of multiple climate variables in the Beijing-Tianjin-Hebei region of China. J Appl Meteorol Climatol 58:2387-2403

Hao ZX, Xiong DY, Ge QS (2018) Reconstruction of the chronology and characteristics of flood disasters in the Xiong'an New Area over the last 300 years. Chin Sci Bull 63:2302-2310 
Jiang RG, Yu X, Xie JC, Zhao Y (2018) Recent changes in daily climate extremes in a serious water shortage metropolitan region, a case study in Jing-Jin-Ji of China. Theor Appl Climatol 134:565-584

Kang S, Eltahir EAB (2018) North China Plain threatened by deadly heatwaves due to climate change and irrigation. Nat Commun 9: 2894

Li L, Chan PW, Wang D, Tan MY (2015) Rapid urbanization effect on local climate: intercomparison of climate trends in Shenzhen and Hong Kong, $1968-2013$. Clim Res 63:145-155

Li RK, Han ZY, Xu Y, Shi Y et al (2020) An ensemble projection of GDP and population exposure to high temperature events over Jing-Jin-Ji district based on high resolution combined dynamical and statistical downscaling datasets. Climate Change Research, in press.

Ma ZG, Ren XB (2007) Drying trend over China from 1951 to 2006. Adv Clim Chang Res 3:195-201

Mei C, Liu JH, Chen MT, Wang H et al (2018) Multi-decadal spatial and temporal changes of extreme precipitation patterns in northern China (Jing-Jin-Ji district, 1960-2013). Quat Int 476:1-13

National Standard of People's Republic of China GB/T 20481-2006 (2006) The grade of meteorological drought. China Standard Press, Beijing

Qian C, Cao LJ (2018) Linear trends in mean and extreme temperature in Xiongan New Area, China. Atmospheric and Oceanic Science Letters 11:246-254

Qin DH, Zhang JY, Shan CC, Song LC (2015) China National Assessment Report on Risk Management and Adaptation of Climate Extremes and Disasters. Science Press, Beijing

Shi Y, Han ZY, Xu Y, Wu J (2019) Future changes of climate extremes in Xiong' an New Area and Jing-Jin-Ji district based on high resolution $(6.25 \mathrm{~km})$ combined statistical and dynamical downscaling datasets. Clim Chang Res 15:140-149

Sun Y, Zhang XB, Ren GY, Zwiers FW et al (2016) Contribution of urbanization to warming in China. Nat Clim Chang 6:1-6
Wang YJ, Song LC, Ye DX, Wang Z et al (2018) Construction and application of a climate risk index for China. J Meteor Res 33: 937-949

Wu J, Gao XJ (2013) A gridded daily observation dataset over China region and comparison with the other datasets. Chin J Geophys 56: $1102-1111$

Wu S, Dai E, Ge Q (2011) The comprehensive risk prevention: Chinese comprehensive climate change risks. Science Press, Beijing

Wu J, Gao XJ, Xu Y (2018) Climate change projection over Xiong'an District and its adjacent areas: an ensemble of RegCM4 simulations. Chin J Atmos Sci 42:696-705

Xia J, Zhang YY (2017) Water resource and pollution safeguard for Xiongan New Area construction and its sustainable development. Bull Chin Acad Sci 32:1199-1205

Xie WS, Wu R, Ding XJ (2018) Risk assessment and early warning of urban waterlogging based on FloodArea model. Resources and Environment in the Yangtze Basin 27:2848-2855

Xu Y, Zhang B, Zhou BT, Dong SY et al (2014) Projected flood risks in China based on CMIP5. Adv Clim Chang Res 5:57-65

Zhai PM, Yuan YF, Yu R, Guo JP (2018) Climate change and sustainable development for cities. Chin Sci Bull 64:1995-2001

Zheng ZF, Gao H, Wang ZW, Liu W (2012) Numerical simulation for the urbanization effects on a heat wave event around Beijing city. Ecol Environ Sci 21:1689-1694

Zhu J, Ma ZG, Yan ZW, Yuan X et al (2017) Problems faced by construction of Xiongan New Area under climate change. Bull Chin Acad Sci 32:1231-1236

Zhu R, Zhang CJ, Mei M (2018) The climate characteristics of atmospheric self-cleaning ability index and its application in China. China Environ Sci 38:3601-3610

Publisher's note Springer Nature remains neutral with regard to jurisdictional claims in published maps and institutional affiliations. 